\title{
A disciplina de Pesquisa e Processos Educativos como articuladora da prática e da pesquisa em sala de aula
}

\author{
The discipline of Research and Educational Processes as an articulator \\ of research practice in the classroom
}

\author{
Anelise Grünfeld de Luca e-mail (anelise.luca@ifc.edu.br) \\ Instituto Federal Catarinense
}

\author{
Marilândes Mól Ribeiro de Melo e-mail (marilandes.melo@ifc.edu.br) \\ Instituto Federal Catarinense
}

\begin{abstract}
Resumo: O presente artigo teve como objetivo analisar a disciplina Pesquisa e Processos Educativos (PPE), como um componente voltado a instigar os licenciandos a praticar a pesquisa em sala de aula. Especificamente pretendeu-se apresentar e analisar as temáticas abordadas nos projetos elaborados entre os anos de 2017 a 2019, buscando entender as intencionalidades, as possibilidades e os desafios relacionados ao desenvolvimento das pesquisas realizadas nesta disciplina numa perspectiva de reflexão e reconstrução do ser e estar professor pesquisador da sua prática. A PPE é uma disciplina desenvolvida no curso de licenciatura em Química nos primeiros quatro semestres (PPE I a IV) com carga horária total de 360 horas, nas quais o licenciando deverá compreender a realidade educacional, bem como caracterizar os aspectos da rede de ensino local, tornar-se autônomo e proativo. Firma-se assim, o argumento defendido por Pedro Demo que compreende a pesquisa como razão do ensino, e este, como razão da pesquisa em sala de aula, posto que o futuro professor se conscientiza de que não há ensino sem pesquisa e que a ausência desta, pode degradar o ensino, reduzindo-o práticas imitação.
\end{abstract}

Palavras-chave: Pesquisa em sala de aula; Pesquisa e Processos Educativos; Formação de professores.

Abstract: This article aims to analyze the subject Research and Educational Processes (REP), as a subject aimed to encourage undergraduate students to practice research in the classroom. Specifically, it is intended to present and analyze the issues addressed in the projects developed between the years 2017 to 2019, seeking to understand the intentionality, possibilities, and challenges related to the development of research carried out in this subject in a perspective of reflection and reconstruction of being a teacher-researcher of your practice. REP is a subject studied in the Chemistry Education Degree in the first four semesters (REP I to IV) with a total of 360 hours, in which the students must understand the educational reality, as well as to characterize the aspects of the local education network, become autonomous and proactive. Thus, through the development of this subject, we assert the argument of Demo (2006), research as a reason for teaching, and teaching as a reason for research in the classroom, since the future teacher becomes aware that there is no teaching without research and that the absence of this, can degrade teaching, reducing to imitation practices. 
Keywords: Classroom research; Research and Educational Processes; Teacher training.

\section{INTRODUÇÃO}

A pesquisa constitui-se em um elemento essencial na formação docente; isto tem sido apontado por pesquisadores da área de educação. Pensar na integração entre ensino e pesquisa é viabilizar novas perspectivas para a formação do professor tendo como foco o professor pesquisador. A relação intrínseca entre ensino e pesquisa revela a importância de atividades de pesquisa na formação inicial de professores, considerando que esta propicia a melhoria do desempenho do docente em sala de aula, oportunizando novos olhares sobre os fenômenos escolares, favorecendo o trabalho de investigação (PERRENOUD, 1993; ZEICHNER, 1993). Santos (2012) enfatiza que a formação do professor pesquisador deve buscar a compreensão de que o trabalho docente requer constantes questionamentos e a procura de soluções criativas para as problemáticas reais, vivenciadas no contexto escolar. Artigos devem apresentar resumo e palavraschave no mesmo idioma em que o texto foi escrito e em uma língua estrangeira, em Inglês ou Espanhol ou ainda em Português quando o original for submetido por autores estrangeiros.

A ênfase nesse tipo de formação está no desenvolvimento de uma atitude investigativa por parte do professor, detectando problemas, procurando, na literatura educacional, na troca de experiência com os colegas e na utilização de diferentes recursos, soluções para encontrar formas de responder aos desafios da prática, independentemente desse atribuir ou não o rótulo de pesquisa a esse tipo de atividade (SANTOS, 2012, p. 24).

É preciso refletir que, para formar um professor pesquisador, é necessário promover a pesquisa na sua formação inicial, possibilitando atitudes que viabilizem o questionamento, a reflexão e a crítica frente à realidade do cotidiano escolar. A promoção da pesquisa nessa perspectiva lança um olhar para a sala de aula como um espaço por excelência para se pensar e fazer a pesquisa fundamentada e interessada em aspectos que problematizam os elementos essenciais da docência em consonância com os da pesquisa.

Percebe-se que a pesquisa apresenta diferentes abordagens em campos científicos distintos, o que permite analisar o termo como polissêmico. A pesquisa no ensino superior é concebida, "[...] como atividade científica pensada pelas Ciências Exatas e Humanas através de linhas de pensamentos distintos (SANTANA; ARAÚJO, 2014, p. 
2932), “[...] é caracterizada por um conjunto de princípios e orientações para procedimentos e está sujeita à avaliação em termos de validade, confiabilidade e representatividade" (MOREIRA; CALEFFE, 2014, p. 17). Quando a pesquisa acontece na educação básica, este conceito se reduz, empobrecendo o seu fazer, relacionado exclusivamente em atividades práticas, cópias e recortes de textos da internet e livros, entre outras ações (BAGNO, 2007).

Pode-se afirmar que a escola não orienta os alunos em como pesquisar; é preciso ensinar a aprender, criando possibilidades para que os alunos busquem as fontes de conhecimento que estão à disposição na sociedade. Ainda é importante considerar que “[...] os cursos de formação de professores, em geral, deixam de lado esse componente importantíssimo e se concentram nas metodologias que facilitam a transmissão de conteúdos" (BAGNO, 2007, p. 15). Esta constatação contribui para entender que a escola de educação básica não privilegia uma prática de pesquisa e, principalmente, não são desenvolvidas com os alunos as habilidades de pesquisar e elaborar projetos.

Tendo em vista tais implicações é que se deve promover a pesquisa na formação inicial dos professores, buscando fomentar desde o início do curso, o pensar, o planejar e o fazer pesquisa, como algo que faz parte da atividade docente, que envolve os sujeitos, alunos e professores, num processo de questionamento, que propicia a construção de argumentos e a comunicação. Entendendo a realidade num sentido dialético que emerge em um movimento permanente de transformação. (MORAES; GALIAZZI; RAMOS, 2012).

Assim sendo, este artigo objetivou analisar a disciplina Pesquisa e Processos Educativos (PPE), como um componente voltado a instigar os licenciandos a praticar a pesquisa em sala de aula. Especificamente foram analisadas as temáticas abordadas nos projetos elaborados entre os anos de 2017 a 2019, buscando entender as intencionalidades, as possibilidades e os desafios relacionados ao desenvolvimento das pesquisas realizadas nesta disciplina numa perspectiva de reflexão e reconstrução do ser e estar professor pesquisador da sua prática.

\section{ANOTAÇÕES SOBRE A FORMAÇÃO DE PROFESSORES NO BRASIL}


Diniz-Pereira (2013, p. 146) ao analisar a construção do campo da pesquisa sobre formação de professores mostra que os movimentos iniciais datam do ano de 1973, quando a "comunidade internacional em pesquisa educacional definiram um marco para o surgimento ${ }^{1}$ desse campo no mundo: a publicação de uma revisão da literatura especializada, realizada por Robert F. Peck e James A. Tucker, na edição de 1973 do Handbook of Research on Teaching". Ele assinala também que esse marco não desconsidera que pesquisa sobre a formação de professores acontecesse antes desse período; no entanto, até o ano 1973, “a comunidade internacional de pesquisadores em educação [...] não admitia seu status como linha de pesquisa”.

Já no Brasil, os debates e pesquisas sobre esse tema estão contemplados em cinco períodos: de 1972 a 1981; de 1982 a 1985; de 1988 a 1994; de 1990 a 1998; 1997 a 2002, que instalam na cena para o debate as pesquisadoras Maria das Graças Feldens, Vera Candau, Menga Lüdke, Marli André e Iria Brzezinski, respectivamente (DINIZPEREIRA, 2013, p. 146). Diniz-Pereira explicita também que

Uma boa parte da produção acadêmica sobre formação de professores no
Brasil, principalmente aquela divulgada por meio de livros, capítulos de
livros e artigos de periódicos, não necessariamente baseia-se em resultados
de pesquisa. São textos que discutem e analisam a situação da formação
docente ou as políticas públicas voltadas para a preparação dos profissionais
da educação no país, sem a preocupação com a apresentação de dados
empíricos ou a explicitação de referenciais teóricos de análise (DINIZ-
PEREIRA, 2013, p. 146).

Gatti (2010) ao analisar a formação de professores no Brasil, compreende que o cenário é inquietante e considera um conjunto de fatores que se referem a legislação que rege a formação; as características sociais e educacionais dos "candidatos a professor (a)"; as características dos cursos, os currículos e as ementas, apresenta algumas características sobre o processo formativo do professor:

A profissionalidade é o conjunto de características de uma profissão que enfeixam a racionalização dos conhecimentos e habilidades necessárias ao exercício profissional, e que a profissionalização de professores implica a obtenção de um espaço autônomo, próprio à sua profissionalidade, com valor claramente reconhecido pela sociedade (GATTI, 2010, p. 1360).

O crescimento relativo dos cursos de formação de professores mostra que uma incidência entre $52 \%$ a $94 \%$ dos cursos analisados persegue o objetivo de formar professores polivalentes. Ela demonstra também que as universidades são as

\footnotetext{
${ }^{1} \mathrm{O}$ grifo é do autor.
}

Recebido em: $01 / 09 / 2020$

Aceito em: $27 / 10 / 2020$ 
responsáveis por cerca de " $63 \%$ desses cursos e, quanto ao número de matriculados, a maior parte está nas instituições privadas: 64\% das matrículas em Pedagogia e 54\% das matrículas nas demais licenciaturas" (GATTI, 2010, p. 1361). Afirma ainda em seus estudos que no que diz respeito à escolha pelo curso de Licenciatura, exceto a Pedagogia, a opção pela docência emerge como "uma espécie de 'seguro desemprego', ou seja, como uma alternativa no caso de não haver possibilidade de exercício de outra atividade, é relativamente alta (21\%), sobretudo entre os licenciandos de outras áreas" (GATTI, 2010, p. 1361). A mesma pesquisadora argumenta:

\begin{abstract}
Não há consistência em uma profissionalização sem a constituição de uma base sólida de conhecimentos e formas de ação. Com estas conceituações, estamos saindo do improviso, da ideia do professor missionário, do professor quebra-galho, do professor artesão, ou tutor, do professor meramente técnico, para adentrar a concepção de um profissional que tem condições de confrontar-se com problemas complexos e variados, estando capacitado para construir soluções em sua ação, mobilizando seus recursos cognitivos e afetivos (GATTI, 2010, p. 1360).
\end{abstract}

Os cursos de licenciatura de acordo com a legislação, tem como finalidade formar professores para atuarem na educação básica, ensino fundamental, ensino médio, ensino profissionalizante, educação de jovens e adultos e educação especial. Uma das preocupações com as licenciaturas diz respeito às instituições que oferecem o referido curso, bem como seus currículos e conteúdos ministrados. Muitas vezes a responsabilidade do mau desempenho das redes de ensino recai sobre o professor e sua formação; cabe lembrar que além desse, existem múltiplos fatores que colaboram para a triste realidade em que o país se encontra na questão da educação (GATTI, 2010). A procura constante por uma formação de qualidade para os profissionais da educação são essenciais para buscar nas escolas e nas salas de aula, melhores oportunidades de formação para as futuras gerações garantindo o seu desenvolvimento.

De acordo com Lüdke e Cruz (2005, p. 93) as licenciaturas têm sido muito debatidas no cenário educacional. As pesquisadoras mostram "limitações que cercam sua estruturação" e a perpetuação do "velho" modo $3+1$ ", que eternizam "o predomínio da formação dos conteúdos em relação à formação pedagógica, provocando a separação entre as duas dimensões e, geralmente, considerando a licenciatura como um apêndice do bacharelado". Entendem que 
O currículo dos cursos de formação organizados nessa perspectiva apresenta, geralmente, uma ciência básica, uma ciência aplicada e, finalmente, um espaço de ensino prático, no qual se espera que os alunos aprendam a aplicar o conhecimento adquirido aos problemas da prática cotidiana (LÜDKE; CRUZ, 2005, p. 93).

Quando refletem sobre o mesmo aspecto Melo e Luca (2020, p. 2) compreendem que

\begin{abstract}
Este modelo formativo não atende completamente às práticas pedagógicas, que por sua complexidade necessitam que as respostas para os problemas sejam oriundos dos próprios contextos nos quais o licenciado atua. Ao chegar ao curso superior o aluno se depara com o conhecimento teórico, porém muitas vezes, é difícil relacionar teoria e prática se o licenciando não vivenciar momentos reais nos quais será preciso conviver em sala de aula.
\end{abstract}

Nesse aspecto, a pesquisa quando é reconhecida como componente relevante no processo de formação de professores dá uma contribuição significativa sobre o problema quando pensa um professor mais dinâmico, ativo e autônomo nos seus processos de decisão, atribuindo-lhe a característica de professor reflexivo/pesquisador (SCHÖN, 1992).

3. A FORMAÇAO DE PROFESSORES NO CURSO DE LICENCIATURA EM QUÍMICA NO INSTITUTO FEDERAL CATARINENSE - CAMPUS ARAQUARI

A formação de professores não pode se guiar por representações inibidoras do que é a pesquisa; ou seja, curvar-se à tendência acadêmica, sem dedicar-se aos problemas reais da escola. Demo (2012) mostra que nos cursos de graduação a marca por excelência é o ensino e que tal condição denota que a função do docente é repassar conhecimentos. O pesquisador afirma que "em vez de ser apenas princípio científico, pesquisa desempenha igualmente a função de princípio educativo" (DEMO, 2012, p. $83)$.

Tal perspectiva se torna ainda mais grave quando se pensa esta prática na Educação Básica. A pesquisa em sala de aula circunda os agentes envolvidos com o processo educativo e orienta a problematizar discursos e verdades estabelecidas, na busca da construção de argumentos de novas verdades: aquelas que refutam uma realidade acabada, e a pensam enquanto construção humana ao longo dos processos históricos. 
Ela emerge então como princípio formativo na formação do professor, possibilitando que ele intervenha, investigue, visando a transformação da realidade na qual exerce sua função. A pesquisa se materializa então como princípio científico e educativo que compõe "todo o processo emancipatório, no qual se constrói o sujeito histórico autossuficiente, crítico e autocrítico, participante e capaz de reagir contra a situação de objeto e de não cultivar o outro como objeto" (DEMO, 2006, p.42- 43). Ela assume o caráter de espaço para o diálogo e

\begin{abstract}
processo cotidiano integrante do ritmo de vida, produto e motivo de interesses sociais em confronto, base da aprendizagem que não se restrinja a mera reprodução; Na acepção mais simples, pode significar conhecer, saber, informar-se para sobreviver, para enfrentar a vida de modo consciente (DEMO, 2006, p. 42- 43).
\end{abstract}

Quando se trata da articulação do binômio educação e qualidade, sem dúvida a pesquisa em sala de aula é um dos fatores que contribui para a qualificação socialmente referenciada de ambos, considerando que "a qualidade formal do conhecimento e da educação é instrumento primordial de inovação" (DEMO, 1994, p. 47). A qualidade da educação orienta-se pelas possibilidades humanizadoras de um agente histórico capaz de "manejar e produzir conhecimentos" como "força inovadora primordial, que decide, mais que outros fatores, cidadania" (DEMO, 1994, p. 47). Neste aspecto a pesquisa precisa ser reconhecida como condição da docência, como princípio educativo que promove uma formação crítica capaz de "conceder" cidadania como "um fenômeno que se nutre da inter-relação entre consciência crítica e capacidade de tomar iniciativa" (DEMO, 1994, p. 50).

É nesta perspectiva que a partir do ano de 2008, com a instituição da Rede Federal de Educação Profissional, Científica e Tecnológica, que foram criados por meio da Lei $N^{\circ}$ 11.892, de 29 de dezembro de 2008, os Institutos Federais de Educação, Ciência e Tecnologia. A estas instituições cabe o compromisso de ofertar 50\% de educação profissional técnica de nível médio e $20 \%$ de cursos de licenciatura, de programas especiais de formação pedagógica objetivando formar professores para a educação básica, especialmente para as áreas de ciências e matemática, e para a educação profissional.

É neste contexto que o Instituto Federal - Campus Araquari se insere. Ele está localizado às margens da BR-280, rodovia que liga os municípios de Joinville (distante 20 km do centro), Araquari e São Francisco do Sul (distante 18 km). O IFC - Campus 
Araquari, tem formado e inserido no mundo do trabalho ao longo dos seus 50 anos de existência, profissionais especializados no setor agropecuário. Foi criado por meio do acordo articulado entre a União e o Estado de Santa Catarina no dia 26 de fevereiro de 1954, e consolidado pela publicação no Diário Oficial da União/DOU n o 63, de 18 de março de 1954 e iniciou suas atividades como Colégio Agrícola Senador Carlos Gomes de Oliveira (CASCGO) no ano de 1959.

Melo e Luca (2020, p. 8) ao analisarem as experiências de estágio supervisionado obrigatório realizadas na instituição esclarecem sobre os cursos ofertados:

O Campus Araquari oferece 05 (cinco) cursos superiores, 03 (três) de Bacharelado (Medicina Veterinária, Sistemas de Informação e Agronomia), 02 (dois) de Licenciatura (Química e Ciências Agrícolas), bem como 02 (dois) Cursos de pós- graduação Lato Sensu (Produção em Aquicultura e Educação em Matemática) e 01 (um) curso de pós-graduação Stricto Sensu (Produção e Sanidade Animal). Além destes, oferece diversos cursos técnicos de nível médio.

Atualmente o IFC - Campus Araquari oferta também o curso de pós-graduação Stricto Sensu em Tecnologia e Ambiente. No que concerne à formação de professores dois cursos se destacam: Licenciatura em Química e em Ciências Agrícolas. De acordo com o Projeto Político Pedagógico (PPCS) do curso de Licenciatura em Química esta formação principia

Atender ao mundo do trabalho, suprindo profissionais diferenciados para atuarem na docência da educação básica. O profissional Licenciado em Química também pode dedicar-se à pesquisa acadêmica, visando a geração de novos conhecimentos, materiais didáticos e metodologias ou atuar na área de análises químicas e controle de qualidade, quer no desenvolvimento de novos métodos analíticos, quer na operação de equipamentos. Outra opção é poder atuar nas diversas fases da produção industrial nos mais variados segmentos como farmacêutico, alimentício, de cosméticos, agricultura, siderúrgica, entre outros (PPCS, 2017, p. 18).

No que diz respeito aos professores de química a carência de docentes com formação especifica é notória:

No ensino de química, 9,23\% dos professores de Santa Catarina não possuem nível superior. Essas carências são maiores em municípios mais afastados dos centros de formação, em geral, pequenos municípios, com escolas menores. Os docentes sem a qualificação exigida por lei ministram aulas, muitas vezes, para mais de uma turma. Em Santa Catarina, 38,3\% deles ensinam para cinco ou mais turmas (MELO; LUCA, 2020, p. 8). 
No campus Araquari o curso de Licenciatura em Química data de 09/09/2010, quando por meio da Resolução Ad Referendum $\mathrm{n}^{\circ} 026$ do Conselho Superior (Consuper) passou a operar ofertando 40 vagas anualmente. Como objetivo primordial visa "atender ao mundo do trabalho, suprindo profissionais diferenciados para atuarem na docência da educação básica” (MELO; LUCA, 2020, p. 6).

Toda a regulamentação do curso está articulada as Políticas Institucionais instituídas no Projeto Pedagógico Institucional (PPI), e que prevê tornar o curso um “centro de referência no apoio à oferta do ensino de ciências nas instituições públicas de ensino, oferecendo capacitação técnica e atualização pedagógica aos docentes das redes públicas de ensino" (MELO; LUCA, 2020, p. 6). No Projeto Político Pedagógico deste curso, o perfil profissional Licenciado em Química está desenhado como aquele que

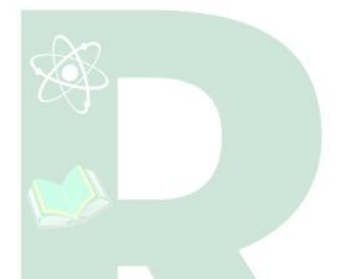

Pode dedicar-se à pesquisa acadêmica, visando a geração de novos conhecimentos, materiais didáticos e metodologias ou atuar na área de análises químicas e controle de qualidade, quer no desenvolvimento de novos métodos analíticos, quer na operação de equipamentos. Outra opção é poder atuar nas diversas fases da produção industrial nos mais variados segmentos como farmacêutico, alimentício, de cosméticos, agricultura, siderúrgica, entre outros (PPCS/2016, p. 18).

Melo e Luca (2020, p. 9) descrevem a estrutura do curso esclarecendo que acontece ao longo de

08 (oito) semestres, em regime presencial, sendo que as cargas horárias estão assim distribuídas: formação geral 540h; aprofundamento e diversificação de estudos das áreas de atuação profissional 1.740h; estudos integradores e atividades teórico-práticas 200h; estágio curricular 405h; Prática como Componente Curricular 405h, perfazendo assim um total de 3.290h (MELO; LUCA, 2020, p. 9).

Esta estrutura, bem como a soma carga horária das disciplinas, atende ao que previa até o ano de 2019, a Resolução CNE/CP 02/2015 para as licenciaturas. Possivelmente passará por reformulações exigidas pela Base Nacional Comum para Formação de Professores da Educação Básica (BNC-Formação), a Resolução No 2, de 20 de dezembro de 2019, o que pode ocasionar consequências no perfil dos egressos do curso, tendo em vista que está fundamentada um modelo de formação docente por competências, de caráter polissêmico, dado o conjunto de matrizes epistemológicas que designam os conhecimentos a serem apropriados tanto pelo docente, como pelos estudantes. Assim é "descartada" a ideia de um docente curioso e que faz da pesquisa um de seus pilares. 
Atualmente o Curso de Licenciatura tem aproximadamente 100 alunos frequentando regularmente as aulas e um total de 21 alunos formados. Desde o ano de 2017, está sendo ofertada a disciplina Pesquisa e Processos Educativos (PPE), que têm proporcionado a relação com a prática da pesquisa em sala de aula.

\section{A DISCIPLINA DE PESQUISA E PROCESSOS EDUCATIVOS COMO ARTICULADORA DA PRÁTICA DA PESQUISA EM SALA DE AULA}

A PPE é uma disciplina desenvolvida no curso de licenciatura em Química nos primeiros quatro semestres; é organizada em quatro módulos independentes (PPE I a IV), com uma carga horária total de 90 horas por módulo e que devem ser articuladas às demais disciplinas ofertadas ao longo do semestre. É caracterizada pelo “desenvolvimento de práticas reflexivas e contextuais que estabelecem relações entre a teoria e a prática, fomentando a experiência da sala de aula, aliando a teoria ao exercício da prática profissional" (PPCCS, 2017, p. 87). Ainda visa fortalecer e fomentar uma maior integração entre os demais componentes curriculares, além de contribuir "para uma sólida formação teórica e interdisciplinar dos profissionais em formação" (PPC, 2017, p. 88). Esses módulos possuem um eixo temático principal, a partir do qual são desenvolvidas as atividades de ensino, pesquisa ou extensão, relacionadas à realidade educacional e à integração com a rede de educação básica local.

Ao cumprir uma carga horária total de 360 horas, o licenciando "deverá ser capaz de entender a realidade educacional, conhecer as características e os principais problemas da rede de ensino local, além de desenvolver autonomia e pro atividade" (PPC, 2017, p. 87). Firma-se assim, por meio do desenvolvimento dessa disciplina o argumento de Demo (2006, p. 50) que afirma a pesquisa como razão do ensino, e este, como razão da pesquisa em sala de aula, posto que o futuro professor se conscientize de que não há ensino sem pesquisa e que a ausência desta, "degrada o ensino a patamares típicos de reprodução imitativa".

A promoção da reflexão, do movimento da leitura e da escrita e de um fazer mais pontual pensando na pesquisa num contexto que ao mesmo tempo é amplo e específico. A amplitude se percebe quando vivencia as problemáticas do contexto escolar e social, da escola como espaço de interações e conflitos, da sala de aula como tempo de ensinar e de aprender e da formação inicial onde o ser/estar professor como profissionalização é essencial; os olhares direcionados para estes cenários possibilita a 
inserção do licenciando e os desafios da investigação para entender melhor a realidade escolar. Radetzke (2019) discute os desafios do ser professor como mediador de ensinar e de aprender de forma significativa, e provoca a reflexão ao se questionar que

Tratar de e sobre constituição docente é sem dúvida um desafio preciso em tempos de recorrência ao profissional Professor como um mediador de conhecimentos, ou mais ousadamente o promovedor de sua construção. Tal pensar remete-se ao diálogo do que queremos do humano nos seres humanos do futuro e acentua-se ao pensar a sala de aula direcionada aos contextos sociais. Tal questionar reflete de forma autêntica e sublime os caminhos/desafios do Ser Professor na formação de cidadãos críticos e autônomos e circunda a colaboração do aluno na construção de suas aprendizagens, sendo instigado a conhecer, testar hipóteses, propor soluções, argumentar e interagir, desafios colocados ao/pelo Professor no desenvolvimento de suas metodologias (RADETZKE, 2019, p. 1).

\subsection{INTENCIONALIDADES INDICADAS NOS TÍTULOS DOS PROJETOS DE PESQUISA ELABORADOS NA PPE I}

A partir das reflexões apresentadas até aqui, contextualizamos a disciplina da PPE, especificamente no enfoque da PPE I, que acontece no primeiro semestre do curso, ministrada por professores de diversas áreas do conhecimento: pedagogia, sociologia, letras e química. Nesta disciplina é elaborado um projeto de pesquisa por cada um dos acadêmicos sobre objetos variados e articulados com a formação de professores de química e qualificados no final da disciplina por uma banca de professores. A proposta da disciplina conforme o projeto pedagógico do curso está associada com pesquisa, promovendo desde o início a imersão do licenciando no ambiente escolar instigando a capacidade de investigação, da leitura e da escrita, visando ampliar seus olhares para os processos profissionais, sociais, científicos, políticos, históricos dentre outros. Nestes contatos iniciais com a pesquisa, distintas temáticas e projetos de pesquisa foram desenvolvidos e intencionalidades apresentadas, como mostra o quadro 1.

Quadro 1 - Temas dos projetos da PPE I e linhas temáticas (destacadas em negrito)

Temas dos projetos da PPE I e linhas temáticas (destacadas em negrito)

\begin{tabular}{|l|l|r}
\hline Ano de 2017 & Ano de 2018 & Ano de 2019 \\
\hline
\end{tabular}




\begin{tabular}{|c|c|c|}
\hline $\begin{array}{l}\text { O uso de ferramentas digitais no } \\
\text { ensino de química: desafios e } \\
\text { possibilidades. TIC }\end{array}$ & $\begin{array}{l}\text { Droga de química! Ensino e } \\
\text { conscientização. CTS }\end{array}$ & $\begin{array}{l}\text { Análise de livros didáticos do } \\
\text { ensino de química do Programa } \\
\text { Nacional do Livro } \\
\text { Didático/PNLD: uma } \\
\text { abordagem sobre orientação } \\
\text { sexual. CA }\end{array}$ \\
\hline $\begin{array}{l}\text { "Energia eólica" carregando } \\
\text { celular de uma forma limpa. } \\
\text { CTS }\end{array}$ & $\begin{array}{l}\text { Educação ambiental: o que } \\
\text { pensam os alunos do curso de } \\
\text { Licenciatura em Química do } \\
\text { primeiro período sobre isso? } \\
\text { EA }\end{array}$ & $\begin{array}{l}\text { Concepções de ética na visão de } \\
\text { estudantes do curso de } \\
\text { Licenciatura em Química do } \\
\text { Instituto Federal Catarinense - } \\
\text { Campus Araquari. FP }\end{array}$ \\
\hline $\begin{array}{l}\text { A produção do álcool a partir da } \\
\text { fermentação da cana de açúcar: } \\
\text { um recurso didático para o } \\
\text { ensino de química no primeiro } \\
\text { ano do ensino médio. EX }\end{array}$ & $\begin{array}{l}\text { A dificuldade na abordagem da } \\
\text { educação ambiental dentro das } \\
\text { salas de aula. EA }\end{array}$ & $\begin{array}{l}\text { Práticas de prevenção de } \\
\text { doenças causadas pela falta de } \\
\text { higienização, de exercícios e de } \\
\text { cuidados psicológicos no curso } \\
\text { de Licenciatura em Química do } \\
\text { Instituto Federal Catarinense - } \\
\text { Campus Araquari. FP }\end{array}$ \\
\hline $\begin{array}{l}\text { Padrões e normas: analisando o } \\
\text { armazenamento dos produtos } \\
\text { químicos do Laboratório de } \\
\text { Química do IFC - Campus } \\
\text { Araquari. EX }\end{array}$ & $\begin{array}{l}\text { A química na visão do aluno do } \\
9^{\circ} \text { ano do ensino fundamental de } \\
\text { escolas públicas. EAP }\end{array}$ & $\begin{array}{l}\text { Concepção de educação } \\
\text { inclusiva dos professores de } \\
\text { química das escolas públicas } \\
\text { estaduais de São Francisco do } \\
\text { Sul. DI }\end{array}$ \\
\hline $\begin{array}{l}\text { Inovações didáticas na formação } \\
\text { de professores. FP }\end{array}$ & $\begin{array}{l}\text { Educação inclusiva para o } \\
\text { ensino de química: metodologias } \\
\text { didáticas para o ensino de } \\
\text { química para estudantes cegos. } \\
\text { DI }\end{array}$ & $\begin{array}{l}\text { As concepções de Iniciação } \\
\text { Científica/IC dos professores de } \\
\text { ciências do Ensino Fundamental } \\
\text { em escolas municipais de } \\
\text { Jaraguá do Sul. EAP }\end{array}$ \\
\hline $\begin{array}{l}\text { Razões para escolher ser } \\
\text { professor (a): o caso dos (as) } \\
\text { estudantes do curso de } \\
\text { Licenciatura em Química do } \\
\text { IFC - Campus Araquari. FP }\end{array}$ & $\begin{array}{l}\text { Jogo didático: uma ferramenta } \\
\text { para o ensino da química. MD }\end{array}$ & $\begin{array}{l}\text { Razões do abandono dos } \\
\text { discentes no primeiro semestre } \\
\text { no curso de Licenciatura em } \\
\text { Química do IFC - Campus } \\
\text { Araquari, nos anos de } 2017 \text { á } \\
\text { 2019. FP }\end{array}$ \\
\hline $\begin{array}{l}\text { Concepções de qualidade de } \\
\text { ensino na visão de professores e } \\
\text { estudantes do curso de } \\
\text { Licenciatura em Química do } \\
\text { Instituto Federal Catarinense - } \\
\text { campus Araquari. FP }\end{array}$ & & $\begin{array}{l}\text { A tabela periódica no plano } \\
\text { nacional dos livros didáticos da } \\
\text { educação básica nos anos de } \\
2017 \text { a } 2019 \text {. CA }\end{array}$ \\
\hline $\begin{array}{l}\text { Európio e suas aplicações na } \\
\text { indústria. EAP }\end{array}$ & & \\
\hline $\begin{array}{l}\text { Arsênio e sociedade: do mal } \\
\text { para o bem. EAP }\end{array}$ & & \\
\hline $\begin{array}{l}\text { Ouro um metal raro e de } \\
\text { aplicações tecnológicas. EAPP }\end{array}$ & & \\
\hline
\end{tabular}


Análise da introdução da química em livros de química geral: implicações para o aprendizado dos ingressantes no curso de licenciatura em química. EAP

Fonte: Elaborado pelas autoras a partir dos projetos de pesquisa desenvolvidos na disciplina de Pesquisa e Processos Educativos I.

No intuito de categorizar os temas dos projetos de pesquisa elaborados pelos licenciandos, optou-se em identificá-los considerando as linhas temáticas utilizadas para submissão dos trabalhos no Encontro Nacional do Ensino de Química - ENEQ (LEAL, 2009, p. 10-11), reformulada a cada evento. As linhas temáticas demonstram como a Educação em Química no Brasil avança e se consolida privilegiando áreas temáticas que se constituem objeto de pesquisa em programas de pós graduação, especificamente na área da Educação em Ciências. São elas: Ensino e aprendizagem (EAP), Formação de Professores (FP), Materiais Didáticos (MD), Linguagem e Cognição (LC), Experimentação no Ensino (EX), História, Filosofia e Sociologia da Ciência (HFC), Educação em espaços não formais e Divulgação Científica (EFD), Tecnologias da Informação e Comunicação (TIC), Educação ambiental (EA), Abordagem Ciência, Tecnologia e Sociedade (CTS), Currículo e Avaliação (CA) e Diversidade e Inclusão (DI).

Um olhar mais atento para os 24 projetos de pesquisa elaborados durante os anos de 2017, 2018 e 2019, permite destacar as intencionalidades dos projetos: 7 (FP), 5 (EAP), 2 (CTS), 2 (EX), 2 (EA), 2 (CA), 2 (DI), 1 (TIC) e 1 (MD). Essas intencionalidades apontam para a diversidade temática em 2017, para as escolhas mais direcionadas e qualificadas nos anos de 2018/2019 e as mudanças pensando a partir da transversalidade na educação em 2019.

A diversidade das temáticas em 2017 aponta para um direcionamento inicial dos professores que ministravam disciplinas naquele semestre por meio do diálogo e orientação desses projetos: Química Geral Experimental I (3 EAP e 1 CTS) e História da Educação (3 FP). Os professores que ministravam a PPE I no ano 2017 e 2018 tinham formação na área de sociologia, letras e química, enquanto que em 2019 estavam a frente da disciplina as áreas de pedagogia e química, essa diversidade possibilitou outros olhares para os temas dos projetos. As escolhas foram promovidas nas discussões 
das aulas, provocadas pela proposição de uma relação e uma necessidade de mobilizar a leitura, a escrita e a pesquisa na formação do professor.

E nessa perspectiva, pensar a elaboração do projeto de pesquisa requer muita leitura e escrita; o desafio posto foi debruçar-se para ler e para escrever, atitudes e habilidades não tão simples, mas imprescindíveis. As leituras não foram corriqueiras e nem tão pouco prediletas; a maioria dos licenciandos não tem hábitos de leitura e escrita, o que tornou mais provocativo este fazer. No entanto, tudo isso se constitui um processo, como bem explicitado por Radetzke (2019, p. 4): “é dialogar a própria formação do Ser Professor, uma formação contínua que se constitui a cada pincelada de uma escrita, acompanhado do percurso de experiências pelas quais vivência”.

Destacam-se termos que exprimem a intencionalidade para a formação de professores num enfoque inovador, pensando na utilização de ferramentas digitais, formas de abordagens dos conteúdos conceituais da química num viés ambientalmente sustentável, integrando saberes das áreas do conhecimento, um olhar mais atento para os livros didáticos, a ludicidade como forma de promover o interesse e interatividade dos alunos e a inclusão que aparece com propriedade, enfatizando as concepções de educação inclusiva e um direcionamento para um ensino de química, mais inclusivo.

As atividades experimentais também foram pensadas nos projetos de pesquisa e apresentaram como finalidades: controle e qualidade dos reagentes de um laboratório e a experimentação contextualizada e interdisciplinar, relacionado com a fermentação da cana de açúcar. E sobre este último tema, "a contextualização e a interdisciplinaridade são importantes para os entendimentos dos diversos fenômenos nos quais estão inseridos os alunos, como cidadãos" (LUCA et al., 2018, p. 18).

Acredita-se que a reflexão sobre a experimentação no ensino "é relevante, pois permite aos estudantes estabelecerem elos entre as explicações teóricas a serem desenvolvidas em sala de aula e as observações possibilitadas por esse tipo de atividade" (ARAUJO; SOUZA; MORAES, 2019, p. 2). Pensando na "viabilização do diálogo, através dos questionamentos propostos pelo professor em seu planejamento, é importante e favorece a investigação" (LUCA et al., 2018, p. 18). E nesse sentido, é essencial a discussão qualificada sobre a experimentação no ensino nos cursos de formação inicial e continuada de professores para que se possa problematizar e "fundamentar-se teoricamente, superando a visão simplista, de que por meio da 
experimentação chega-se às teorias estabelecidas nas Ciências, comprovando-as" (LUCA et al., 2018, p. 18).

Percebe-se que em um dos projetos pensados em 2017, abordou a investigação sobre as razões para a escolha de ser professor, buscando identificar quais desejos são mobilizados para esta decisão. E no ano de 2019, outro projeto pretendia investigar as razões do abandono no curso Licenciatura em Química dos ingressantes. Até pode ser um paradoxo, porém estes dois projetos atentam para duas ações que devem ser refletidas e discutidas na formação do professor, que correspondem às possibilidades e desafios para o futuro do curso de Licenciatura em Química no IFC - Campus Araquari.

\section{CONSIDERAÇÕES}

Promover a articulação da formação com a pesquisa no curso de Licenciatura em Química do IFC - Campus Araquari, aponta para possibilidades geradas na disciplina de PPE I. Pode-se pontuar a urgência da viabilização desses projetos, provocando mais a reflexão e ação para os licenciandos, revestindo de vozes que emanam de um campo vivencial, onde eles são protagonistas. E como tal, precisam se fazer mais presentes e atuantes nas decisões e no percurso formativo.

É fundamental registrar que alguns temas escolhidos e pensados para o projeto de pesquisa continuaram como temas para a elaboração de recursos e estratégias didáticas para as PPE III e IV e também para o Estágio Supervisionado. Essa constatação é relevante, pois demonstra que os temas não são abandonados, são ressignificados em outros momentos, mas no mesmo contexto. As temáticas revisitadas mobilizam novos e outros olhares para o ensino e a aprendizagem, porém com a premissa da importância do pensar e do agir para e na pesquisa educacional: ou seja, como defende Nunes (1992) é intencionar possibilidades de recriação de objetos já considerados "envelhecidos".

Os desafios vislumbrados para a articulação formação e pesquisa, é por excelência o ser/estar professor que lê, escreve, estuda e pesquisa. Isso engloba tanto os discentes quanto os docentes do curso de Licenciatura em Química - Campus Araquari. Há a necessidade e a urgência por um movimento mais presente de pesquisa nos fazeres e saberes dos professores formadores motivando os alunos a desenvolverem uma cultura de professor/pesquisador. 


\section{REFERÊNCIAS}

BAGNO, M. Pesquisa na escola: o que é, como se faz. 21 ed. São Paulo: Loyola, 2007.

DEMO, P. Pesquisa: princípio científico e educativo. 12. Ed. São Paulo: Cortez, 2006.

DEMO, P. Educação e qualidade. Campinas, SP: Papirus, 1994.

DINIZ-PEREIRA, J. E.. A construção do campo da pesquisa sobre formação de professores. Revista da FAEEBA-Educação e Contemporaneidade, v. 22, n. 40, p. 145-154, 2019.

GATTI, B. A. Formação de professores no Brasil: Características e problemas. Educ. Soc., Campinas, v. 31, n. 113, p. 1355-1379, out.- dez. 2010. Disponível em http://www.cedes.unicamp.br (Acesso em 31/05/2017).

LEAL, M. C. Didática da Química: fundamentos e práticas para o Ensino Médio. Belo Horizonte: Dimensão, 2009.

LUCA, A. G. de; SANTOS, S. A. dos; DEL PINO, J. C.; PIZZATO, M. C. Experimentação contextualizada e interdisciplinar: uma proposta para o ensino de ciências. Revista Insignare Scientia - RIS, v. 1, n. 2, 22 ago. 2018.

MELO, M. M. R. de. LUCA, A. G. de. Experiências de estágio supervisionado obrigatório realizadas no Curso de Licenciatura em Química do Instituto Federal Catarinense - Campus Araquari. Revista Brasileira da Educação Profissional e Tecnológica, v.1, 2020.

MORAES, R., GALIAZZI, M. do C., RAMOS, M. G. Pesquisa em sala de aula: fundamentos e pressupostos. IN: MORAES, Roque, LIMA, V. M. do R. Pesquisa em sala de aula: tendências para a educação em novos tempos. 3. ed. Porto Alegre: EDIPUCRS, 2012.

MOREIRA, H., CALEFFE, L. G. Metodologia da pesquisa para o professor pesquisador. 2. ed. Rio de Janeiro: Lamparina, 2008.

NUNES, Clarice. História da educação brasileira: novas abordagens de velhos objetos. Teoria \& Educação. n.6, p.151-182, 1992.

PERRENOUD, P. Práticas pedagógicas, profissão docente e formação perspectivas sociológicas. Lisboa: Dom Quixote, 1993.

PROJETO PEDAGÓGICO DE CURSO SUPERIOR (PPCS) Licenciatura em Química, Araquari, 2017.

RADETZKE, F. S. O escrever reflexivo na constituição do Ser Professor. Revista Insignare Scientia - RIS, v.1, n. 3. 17 fev. 2019.

Recebido em: $01 / 09 / 2020$

Aceito em: $27 / 10 / 2020$ 
SANTANA, I. C. H., ARAÚJO, A. V. de, ARAÚJO, A. de S. Pesquisa e Ensino na Educação Básica: Dilemas e conflitos na Construção do professor pesquisador. Revista SBEnbio: n.7 outubro 2014.

SCHÖN, D. A. Formar professores como profissionais reflexivos. In: NÓVOA, A. (coord.). Os professores e sua formação. Trad. Graça Cunha, Cândida Hespanha, Conceição Afonso e José Antônio Souza Tavares. Lisboa: Dom Quixote, 1992, p. 77 91.

SANTOS, L. L. C. P. Dilemas e perspectivas na relação entre ensino e pesquisa. IN: ANDRÉ, $M$. (org.) $O$ papel da pesquisa na formação e na prática dos professores. 12. ed. Campinas, SP: Papirus, 2012.

SILVA, A. C.; SOUZA, G.; MORAES, J. Os Livros Didáticos de Química: uma Análise das Atividades Investigativas. Revista Insignare Scientia - RIS, v. 2, n. 4, p. 1- 19, 19 dez. 2019.

ZEICHNER, K. A formação reflexiva de professores: Ideias e práticas. Lisboa: Educa, 1993. 